\title{
Hydrodynamic simulation of a cloudburst event in Asi Ganga Valley of Indian Himalayan region using MIKE11 and Geomatics techniques
}

\author{
Vasanta G Kumar Villuri ${ }^{\mathbf{1}}$, Kamal Jain $^{\mathbf{2}}$, Ajay Gairola ${ }^{\mathbf{3}}$ and Srinivas Pasupuleti ${ }^{4}$ \\ ${ }^{1}$ Geomatics Section, Department of Mining engineering, Indian Institute of Technology(ISM), \\ Dhanbad-826004, India \\ ${ }^{2}$ Department of Civil engineering, Indian Institute of Technology Roorkee-247667, India; \\ kjainfce@iitr.ac.in \\ ${ }^{3}$ Department of Civil engineering, Indian Institute of Technology Roorkee-247667, India; \\ garryfce@iitr.ac.in \\ ${ }^{4}$ Department of Civil engineering, Indian Institute of Technology(ISM), Dhanbad-826004, India; \\ srinivas@iitism.ac.in \\ ${ }^{*}$ Corresponding Author: Email id: vgkvilluri@iitism.ac.in
}

\begin{abstract}
Cloudburst is one of the most devastating and frequently occurring natural hazardous events in Indian Himalayan region. Localized deep cumulus convective clouds have a capability of giving enormous amount of rainfall over a limited horizontal area, within a short span of time. Whenever, such events occur, lead to flash floods causing landslides, house collapses, dislocation of traffic, and human casualties on a large scale. Therefore, it is necessary to predict the cloudburst inundation zones accurately to avoid damage associated with them. For this, high resolution Digital Elevation Model generated from CartoSat-1 (Stereo pair) were integrated in MIKE 11 Hydrodynamic 1D model to generate longitudinal profile of the study area and to find water level, peak discharge, flow velocity, flow width at different reaches along the Asi ganga and Bhagirathi river, to know the Cloudburst flood inundation scenario. On $3^{\text {rd }}$ August 2012 one of the major Cloudburst event occurred in Asi Ganga Valley in Indian Himalayan region which was considered for simulation of hydrodynamic model. For a Cloudburst event, $100 \mathrm{~mm} / \mathrm{hr}$ rainfall was considered for the simulation of the hydrodynamic model. It is observed that the discharge rise from $50 \mathrm{~m}^{3} / \mathrm{s}$ to $549.164 \mathrm{~m}^{3} / \mathrm{s}$ (an abrupt increase of about 10 times) within $1 \mathrm{hr}$ at Sangamchetty in Asiganga river and at Joshiyara area rise from $600 \mathrm{~m}^{3} / \mathrm{s}$ to $3378.69 \mathrm{~m}^{3} / \mathrm{s}$ (an abrupt increase of about 5 times) within $4 \mathrm{hr}$ in Bhagirathi river. Similarly the water level rises around $3 \mathrm{~m}$ and $6 \mathrm{~m}$ in Asi Ganga and Bhagirathi rivers respectively. Flash Flood inundation areas due to Cloudburst on $3^{\text {rd }}$ August 2012 were demarcated from the simulation results in GIS environment.
\end{abstract}

Keywords - Cloudburst, GIS, MIKE11, DEM, Hydrodynamic model

\section{Introduction}

Cloudburst is an extreme form of rainfall, sometimes mixed with hail and thunder, which normally lasts no longer than a few minutes but is capable of creating floods conditions. It is usually of shower type with a fall rate equal to or greater than $100 \mathrm{~mm} / \mathrm{hr}$. [1]. It leads to flash floods/landslides, house collapse, dislocation of traffic and human casualties on large scale. It occurs very frequently in Himalayan region in Uttarkasi district. On $3^{\text {rd }}$ August 2012 there was cloudburst in Asi Ganga valley and heavy rainfall in upper catchment of Bhagirathi river system, which results peak discharge and overtopping of floods along the river from 
42 Sangamchetty to Joshiyara causing huge damage. The basic objective of this study is to prepare

43 the hydrodynamic simulation for a better understanding of cloudburst events.

44 Remote Sensing and geographic information system are the advanced computer based tools

45 and technique which are helpful in analysing the hydrological works related directly and

46 indirectly [2, 3]. Hydrological and Hydrodynamic research deals with the distribution and

47 circulation of water, and the interaction of water with environment [4, 5]. Distributed

48 hydrological model combine with the remote sensing information provides hazards

49 characteristic and their effects like water logging, soil erosion, flood height, velocity, inundated

50 area etc. along with calibration and validation of the model. The MIKE 11, a robust six point

51 distributed 1D model was used for Hydraulic analysis to calculate the gauge height at the cross-

52 section modelling [6, 7]. Early flood warning system for Langat river basin was developed

53 through the combination of remote sensing and GIS hydrodynamic modelling using MIKE11

54 model [8]. MIKE 11 was used for parameterization and validation of Bagmoti river, Sikkim

55 [9]. Hydrologic model integrate all the physical events leading to better simulation of physical

56 world using Geomatics techniques for hydrologic prediction and for understanding of

57 hydrologic processes. [10-12]. In this study, MIKE 11 model was used to simulate the $3^{\text {rd }}$

58 August 2012 cloudburst events of Asi Ganga valley. For cloudburst events, peak flood

59 discharge, storm runoff depth, flow velocity and flow width were estimated at catchments

60 outlets along the Asi Ganga, Bhagirathi main streams and its tributaries from Sangamchetty to

61 Joshiyara region and validated the result with field observation.

\section{Materials and Methodology}

\subsection{Study area}

The study area Asi Ganga region is in Uttarkashi district, Uttarakhand state. The spatial location of the area varies from $30^{\circ} 57^{\prime} 56^{\prime \prime}$ to $30^{\circ} 43^{\prime} 14^{\prime \prime} \mathrm{N}$ latitude and $78^{0} 28^{\prime} 51$ ' to $78^{0} 26^{\prime} 32$ ' 'E longitude. The total area of the district is about $8016 \mathrm{sq}$. $\mathrm{km}$ with a total population of 329,686. The Asi Ganga valley exhibits characteristically distinct rugged mountainous topography of the both lesser and higher Himalayan terrains. The location map of the probable area of cloudburst in Asi Ganga valley is shown in Fig. 1. The area having several ridges and the ground elevations vary from about 950 to 3045 meters above the mean sea level. The monsoon begins in the first week of June and south west monsoon hits the region in the month of July. Highest rainfall will be received in these months. While August also gets rain, September witnesses the retreat of monsoon. The average amount of rainfall received in southwest monsoon season will be around 1500-2000 mm. 


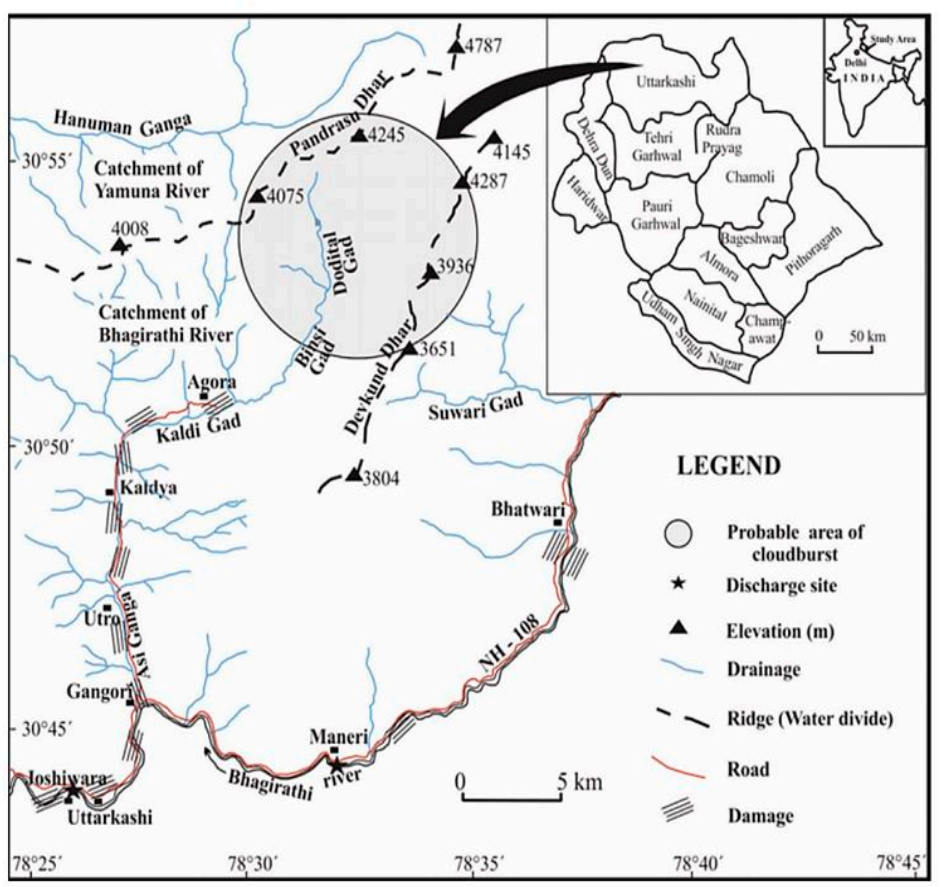

Fig. 1: Location map of the study area depicting the probable area of cloudburst in Asi Ganga Valley (Source-[13])

\subsection{Data used}

The high resolution Cartosat digital elevation model (DEM) procured from NRSC, Resourcesat, Landsat $7 \mathrm{ETM}+$ data set and high resolution satellite images for better visualization were used in this study. The continuous daily and monthly precipitation data was collected from north Ganga Canal Division, Upper Ganga basin, Roorkee. However one hour rainfall data around $100 \mathrm{~mm} / \mathrm{hr}$ was used for simulation of the model (for a cloudburst event). For this purpose, Tropical Rainfall Measuring Mission (TRMM) rainfall data was used for reference. The available discharge data ( $3^{\text {rd }}$ to $5^{\text {th }}$ August 2012) at Joshiyara barrage collected from Uttarakhand Jal Vidyut Nigam Ltd. (UJVNL), Uttarkashi was used for validation of the model. Peak flood data at Joshiyara barrage for the year 2013 on July $17^{\text {th }}$ was used for calibration and field visit data for validation of the model. Total 15 cross sections were surveyed with in which 4 were situated at junction points of Asi Ganga tributaries. In the field visit, monsoon and post monsoon discharge data, base flow, socio economic data, cross section data, verification point data for LULC map, roughness of channel and floodplains, average bottom width of the stream, side slope etc. were collected for MIKE11 model set up.

\subsection{Methodology}

Preparation of MIKE11 model for Asi Ganga valley cloudburst events started with generation of high resolution Digital Elevation model using Cartosat stereo pair data. The collected data was processed as an appropriate thematic map for their direct/indirect usage in hydrodynamic model. The river network file created in HEC-GeoRAS was imported in MIKE11 and the cross sections were extracted from high resolution Cartosat DEM. The boundaries parameters were defined at upstream and downstream side for the river network. At upstream side hydrograph 
98

99

100

101

102

103

104

105

106

107

and downstream side water level were the input. Considering the channel material, amount and type of vegetation cover, channel sinuosity, effect of obstruction etc. roughness values $(\mathrm{N})$ were determined $[14,15]$.

The MIKE 11 model was simulated as unsteady flow for $12 \mathrm{hr}$ time duration (cloudburst event) from 3/8/2012 (12:00:00 hour) to 4/8/2012 (12:00:00 hour). The time step for calculation was taken as 2 seconds. Field visit data and photographs at major locations were used for validation. The peak discharge at Gangori and Joshiyara barrage were used for validation of the simulation model. In field visit, photographs of the flood width and water levels marks on the banks and settlements were considered for validation of simulation model results. The overall methodology of the study is shown in Fig. 2.

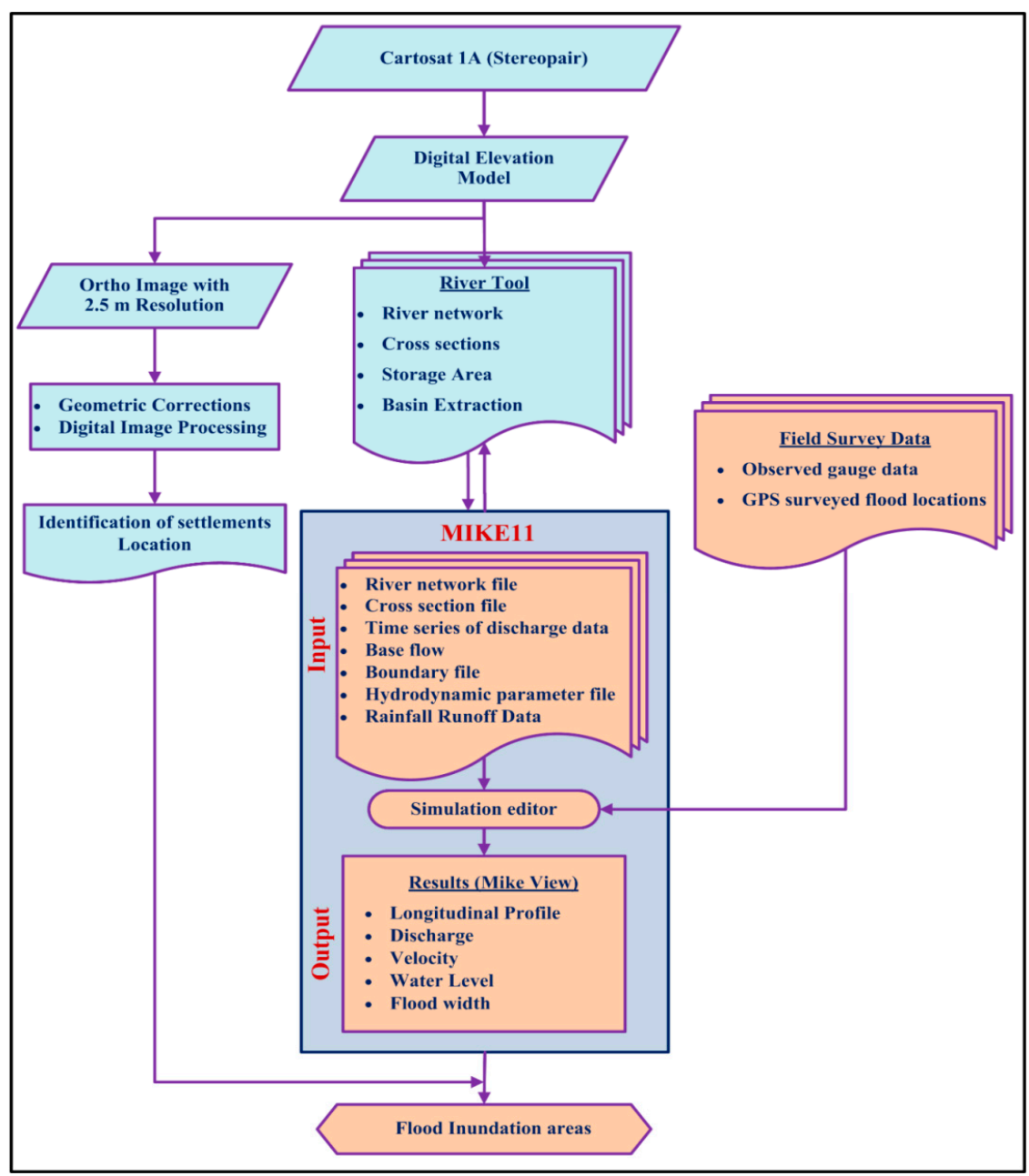

Fig. 2: Flow chart showing overall methodology

\section{Result and Discussion}

\section{$110 \quad 3.1$ Preparation of Thematic layers}

111 The data was processed as an appropriate thematic map for their direct/indirect usage in 112 hydrodynamic model. A high resolution DEM generated by using Cartosat stereo pair data was 
113 used as input to derive various layers and preparation of the database. The area elevation range 114 of the study area varies from $950 \mathrm{~m}$ to $4250 \mathrm{~m}$ as shown in Fig. 3(a). The cloudburst happened 115 at an elevation of $3500 \mathrm{~m}$. The settlements deposited along the Asi Ganga main channel from 116 Sangamchetty with an elevation $1660 \mathrm{~m}$. Slope is an important factor in understanding the 117 surface water movement [16,17]. Slope map of study area was generated using the quadratic 118 surface algorithm developed by Srinivasan and Engel $(1991)[18,19]$, the maximum elevation changes over the distance between the cells and its eight neighbours were slope. The slope of the area varies from flat to very steep slope $0-75^{0}$ degrees is shown in Fig. 3(b). Some settlements are locating where the slope is greater than $35^{\circ}$ which indicates very steep sloping. River in the Asi Ganga valley flowing between $\sim 3400-1200 \mathrm{~m}$ at an average gradient of $\sim 90$ $\mathrm{m} / \mathrm{km}$. Form the slope map, it was observed that the slope patterns in the catchment shows steep slopes towards upper catchment along the northeast to southwest trending. The higher discharge at the catchment outlet raises the height of water of the flash flood and affected a broader area of the slope causing damage to life and property [13, 20]. Although the catchment is small but the high rainfall on a steep slope with very high watercourse triggered widespread runoff that smashed houses, road network and bridges along the channels [20].The land use/land cover is an important characteristic of the runoff process that affects the infiltration, erosion and evapotranspiration. Cartosat-1, Resourcesat- 2 data from LISS III sensor of 3 seasons pertaining to 2011-12 and high resolution satellite imageries were visually interpreted and ground truth information during field work was used to demarcate the land use/land cover features in the Uttarkashi-Gangori-Dodi Tal area. Various image interpretation elements such as colour, shape, size patterns association etc. were taken into consideration to identify various land use/land cover categories. Subsequently field checks were conducted in key areas to checks the veracity of remote sensing data and to incorporate the field knowledge on the map. Five major features were identified to assess their contribution towards runoff are shown in Fig. 3(c). From satellite image interpretation the area has appreciable forest cover up to 80 percent, Scrub forest is about 10 percent, agriculture is restricted to just 5 percent of the total area. This is attributed to the fact that the area is sparsely populated around 5 percent. Streams in the study area are seasonal except river Bhagirathi and Asi Ganga which are perennial. LULC map was used for determining the roughness coefficient along the surveyed crosssection with the help of literature [14]. Streams with micro basins map prepared by HECGeoHMS are_shown in Fig. 3(d).

The various thematic maps of the catchment were utilized for further processing in MIKE 11. The river network file created in HEC-GeoRAS was imported in MIKE 11 network. After generation of river network, cross section were extracted from Cartosat DEM in ArcGIS is shown in Fig. 4(a) and overlaid on Google earth imagery for better visualization shown in Fig. 4(b).The drainage network in MIKE 11 network editor is shown in Fig. 5.The total length of Asi Ganga river was $33 \mathrm{~km}$ from upstream Dodital lake to downstream location at Joshiyara and cross section collected at an interval of $500 \mathrm{~m}$ then those were interpolated by using natural neighbour method. Some cross sections were validated with field visit data. Eight reaches-were identified according to the location of settlements and named as Dhandalka, Naugon, Gajoli, Seku, Ultru, Nair, Mandwa and Khand. The name of reaches, their chainage-wise length in UTM coordinate system and junction hydrodynamic flow are mentioned in Table 1 . The 
156 resistance ratio (observed manning's N / Global manning's $\mathrm{N}$ ) was given as 1 as per the 157 channel/flood plain material [21].

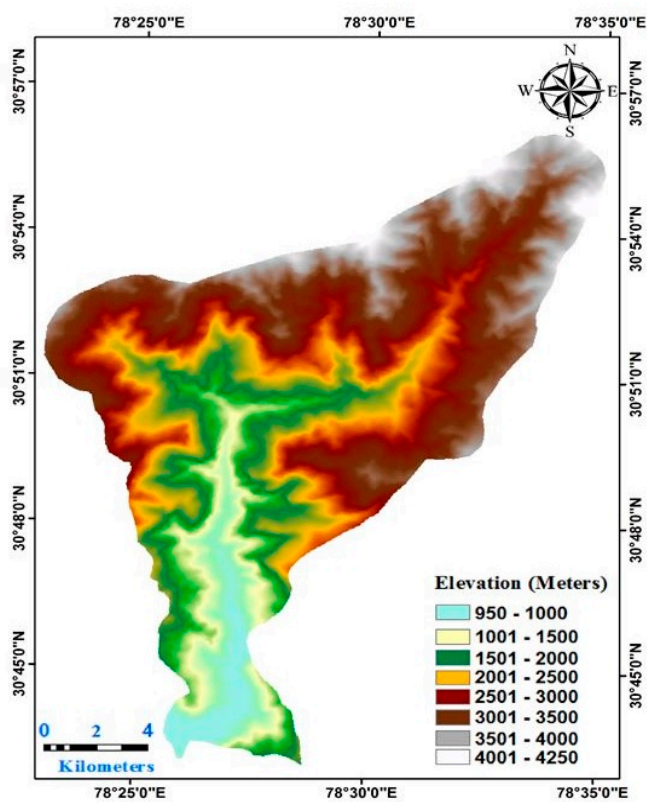

(a)

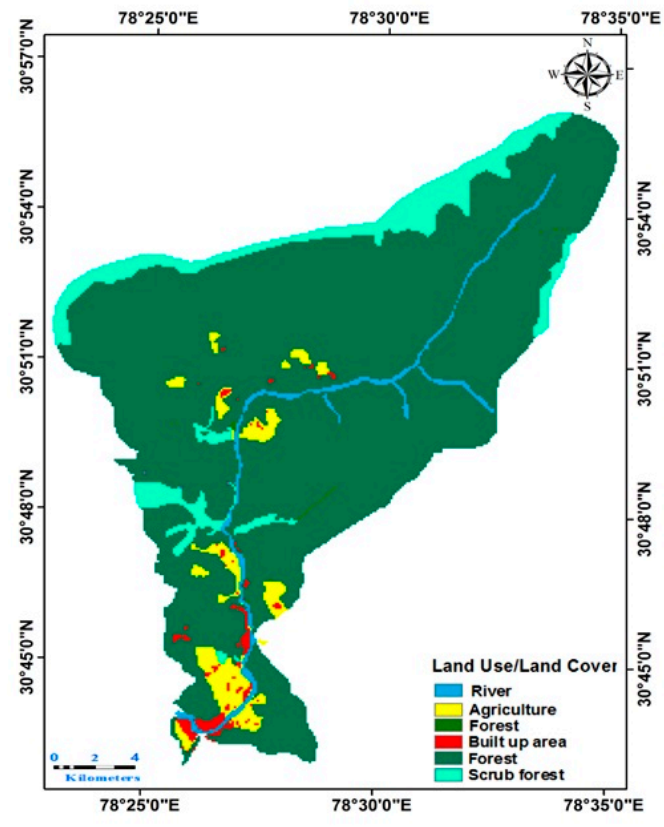

(c)

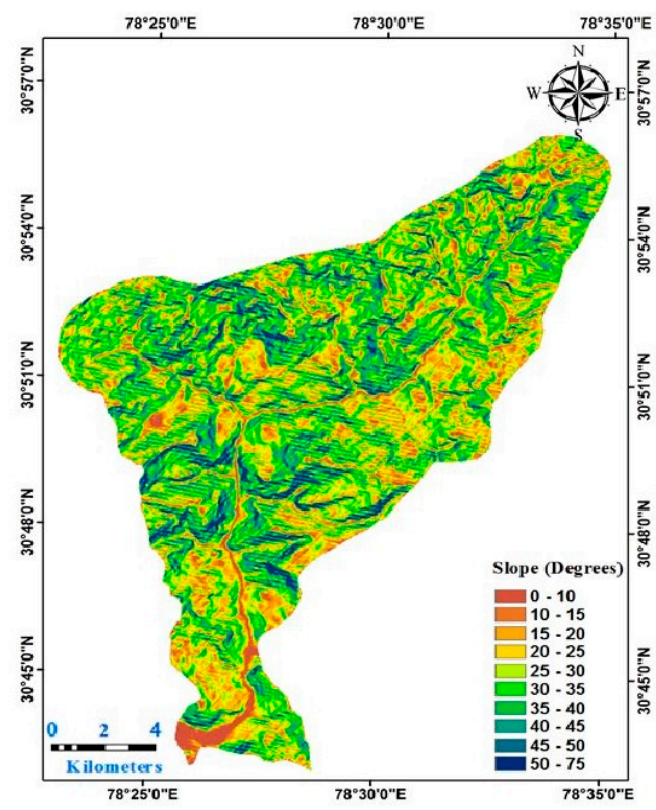

(b)

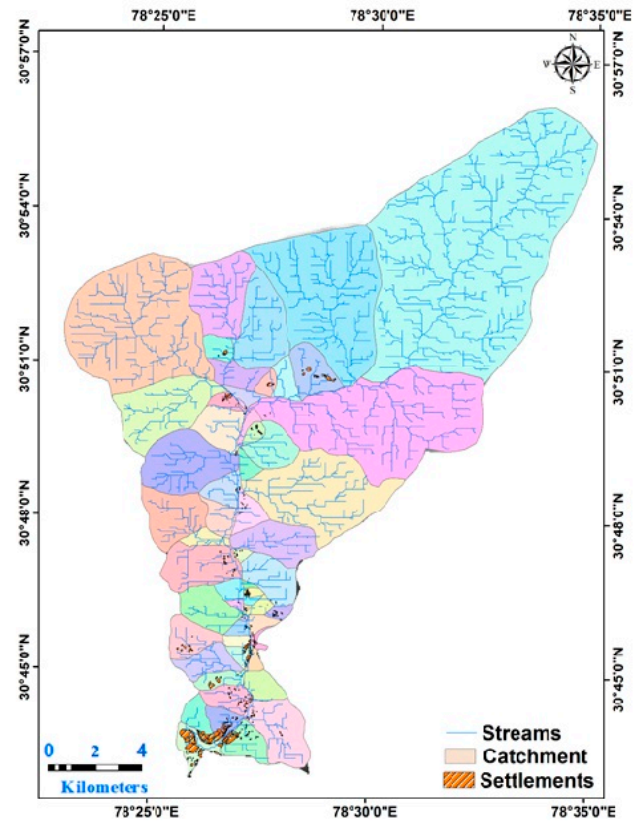

(d)

Fig.3: (a) Elevation Map; (b) Slope map; (c) Land Use / Land Cover map; and (d) Sub catchment area showing with Inhabitations 


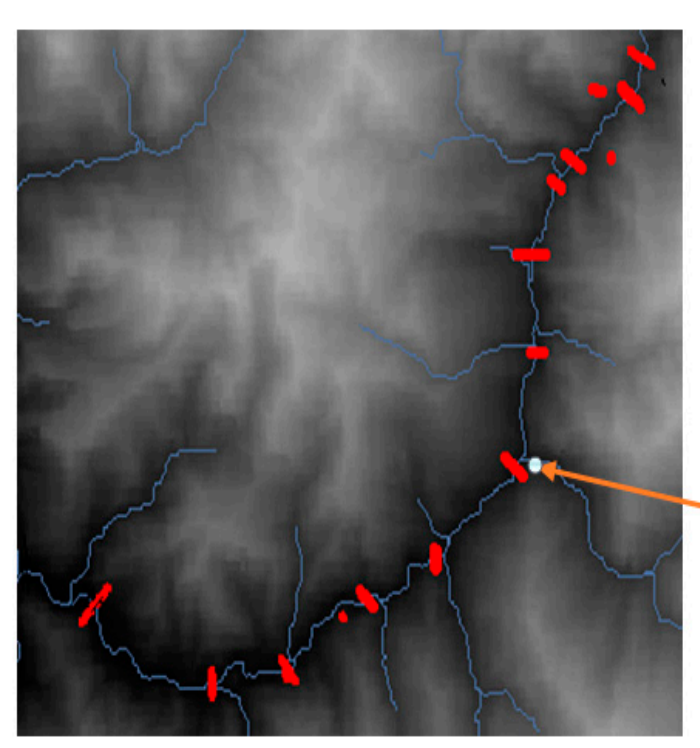

(a)

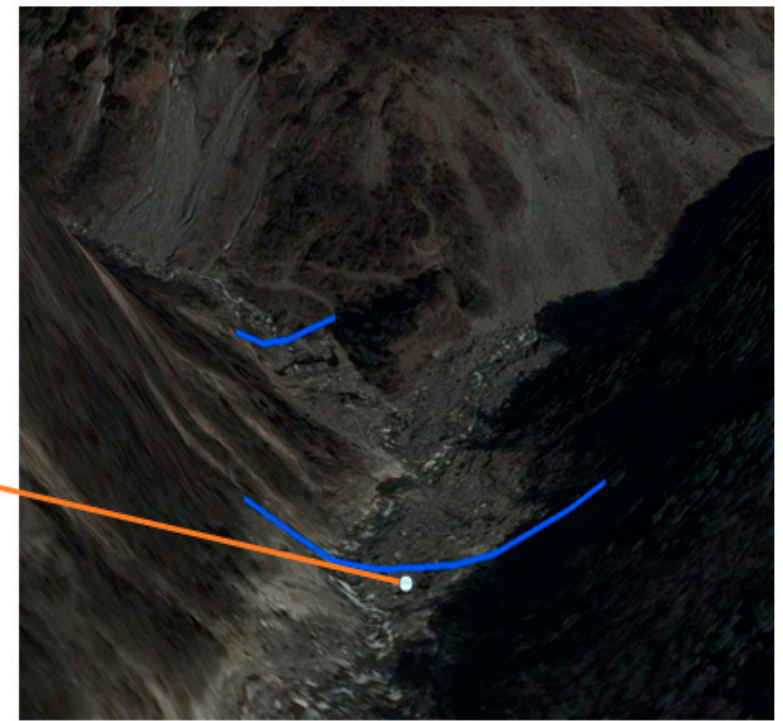

(b)

Fig. 4: (a) Cross Sections extracted from Cartosat DEM; (b) Cross Sections overlayed on high resolution satellite image.

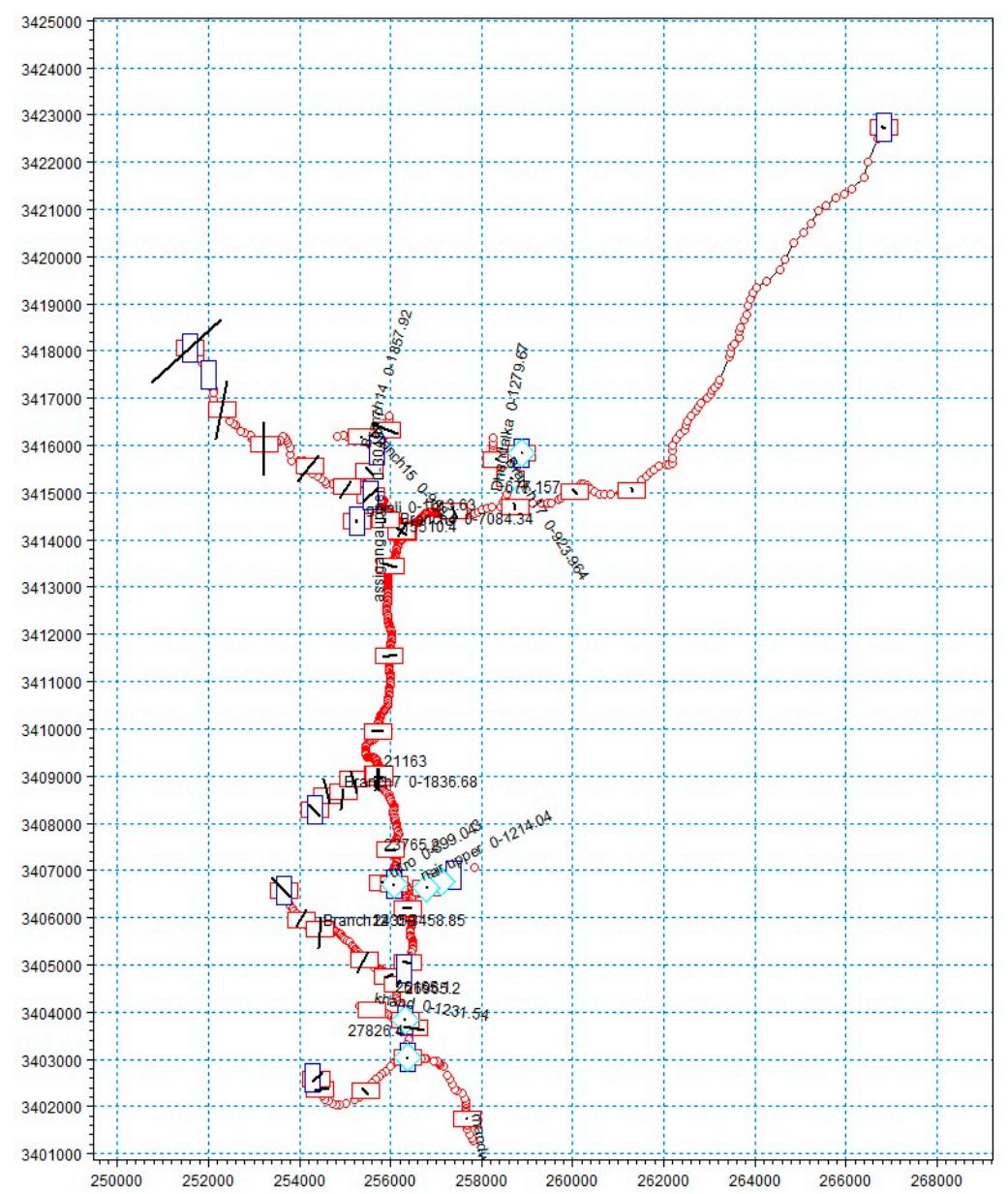

Fig. 5: Drainage network of the study area shown in MIKE11 
Table 1: Cross section Locations according to Reach and chainage

\begin{tabular}{|c|c|c|c|c|c|}
\hline S.No. & Reach Name & Chainage & S.No. & Reach Name & Chainage \\
\hline 1 & Asi Ganga & 0 & 23 & Asi Ganga Tributary 1 & 0 \\
\hline 2 & Asi Ganga & 9929 & 24 & Asi Ganga Tributary 1 & 1575 \\
\hline 3 & Asi Ganga & 11337 & 25 & Asi Ganga Tributary 1 & 2886 \\
\hline 4 & Asi Ganga & 12711 & 26 & Asi Ganga Tributary 1 & 4378 \\
\hline 5 & Asi Ganga & 14112 & 27 & Asi Ganga Tributary 1 & 5386 \\
\hline 6 & $\begin{array}{l}\text { Asi Ganga } \\
\text { (Sangamchetty) }\end{array}$ & 15528 & 28 & Naugon & 0 \\
\hline 7 & $\begin{array}{l}\text { Asi Ganga } \\
\text { (Kaldya School) }\end{array}$ & 16337 & 29 & Naugon & 437 \\
\hline 8 & $\begin{array}{l}\text { Asi Ganga } \\
\text { (Asi Ganga Power } \\
\text { House) } \\
\end{array}$ & 18281 & 30 & Naugon & 1052 \\
\hline 9 & Asi Ganga & 19940 & 31 & Gajoli & 0 \\
\hline 10 & Asi Ganga & 21238 & 32 & Gajoli & 450 \\
\hline 11 & Ultro & 22943 & 33 & Gajoli & 625 \\
\hline 12 & Gangori & 24436 & 34 & Gajoli & 960 \\
\hline 13 & $\begin{array}{l}\text { Bhagirathi } \\
\text { (Gegat) }\end{array}$ & 25660 & 35 & Ultro & 0 \\
\hline 14 & $\begin{array}{l}\text { Bhagirathi } \\
\text { (Tilot) }\end{array}$ & 27226 & 36 & Ultro & 244 \\
\hline 15 & $\begin{array}{l}\text { Bhagirathi } \\
\text { (Uttarkashi) }\end{array}$ & 28963 & 37 & Nair & 0 \\
\hline 16 & $\begin{array}{l}\text { Bhagirathi } \\
\text { (Joshiyara) }\end{array}$ & 30182 & 38 & Nair & 330 \\
\hline 17 & $\begin{array}{l}\text { Bhagirathi } \\
\text { (Joshiyara) }\end{array}$ & 30433 & 39 & Nair & 660 \\
\hline 18 & Dhandalka & 0 & 40 & Khand & 0 \\
\hline 19 & Dhandalka & 485 & 41 & Khand & 300 \\
\hline 20 & Dhandalka & 642 & 42 & Khand & 800 \\
\hline 21 & Dhandalka & 1071 & 43 & Mandwa & 0 \\
\hline 22 & Dhandalka & 1500 & 44 & Mandwa & 300 \\
\hline
\end{tabular}

166 For Rainfall Runoff Modelling, detail of catchments and rainfall distribution file was used as

167 input. The unit Hydrograph model was used for hydrograph generation and Kripich formula 168 was used for Time of concentration. Rational method was used for computation of runoff 
169

hydrograph for each sub catchment. For simulation of model, the discharge from Bhagirathi River was added as a base flow at Gangori after Asi Ganga meets. Due to heavy rainfall in Bhagirathi upper catchment on $2^{\text {nd }}$ and $3^{\text {rd }}$ August 2012, the discharge around $2700 \mathrm{~m}^{3} / \mathrm{s}$ was added as constant flow to Asi Ganga basin. Cloudburst zone wise map is shown in Fig. 6 and area of each catchment is given in Table 2 . The boundary parameters were defined at upstream and downstream side for the river network. At upstream side hydrograph and downstream side water level were the inputs.

The global average value was given for bed roughness as 0.045 . The roughness along main Asi Ganga River and other streams, used here were almost same because of the presence of medium and large size boulders without vegetation cover from channel bottoms to banks for each channels. The Manning's ' $N$ ' values, used in this study for all the reaches vary from 0.030 to 0.070 among all cross-sections. The simulation model was run as unsteady flow for $12 \mathrm{hr}$ time duration (cloudburst event) from 3/8/2012 (12:00 hour) to 4/8/2012 (12:00 hour). The time step for calculation was taken as 2 seconds.

\subsection{Preparation of Hydrodynamic Model}

Initial assumption was that cloudburst happened within a range of 1-5 km. In this study, the model simulated for the case in which Cloudburst happens in Zone 1 and rest of zones are normal rainfall (Actual case). Cloudburst happened in Zone 1 near Dodital on $3^{\text {rd }}$ August 2012 around $7 \mathrm{PM}$. The amount of rainfall used for simulation was $100 \mathrm{~mm} / \mathrm{hr}$ in Zone 1 and $10 \mathrm{~mm} / \mathrm{hr}$ for Z2, Z3, Z4 and Z5 respectively as shown in Fig. 7. The peak flood occurred in Asi Ganga due to Cloudburst from $3^{\text {rd }}$ August 2012 at 20:00:00 hr to $4^{\text {th }}$ August 2012 at 6:00:00 hr. Therefore above time was selected as the simulation period for the respective cloudburst flood event.

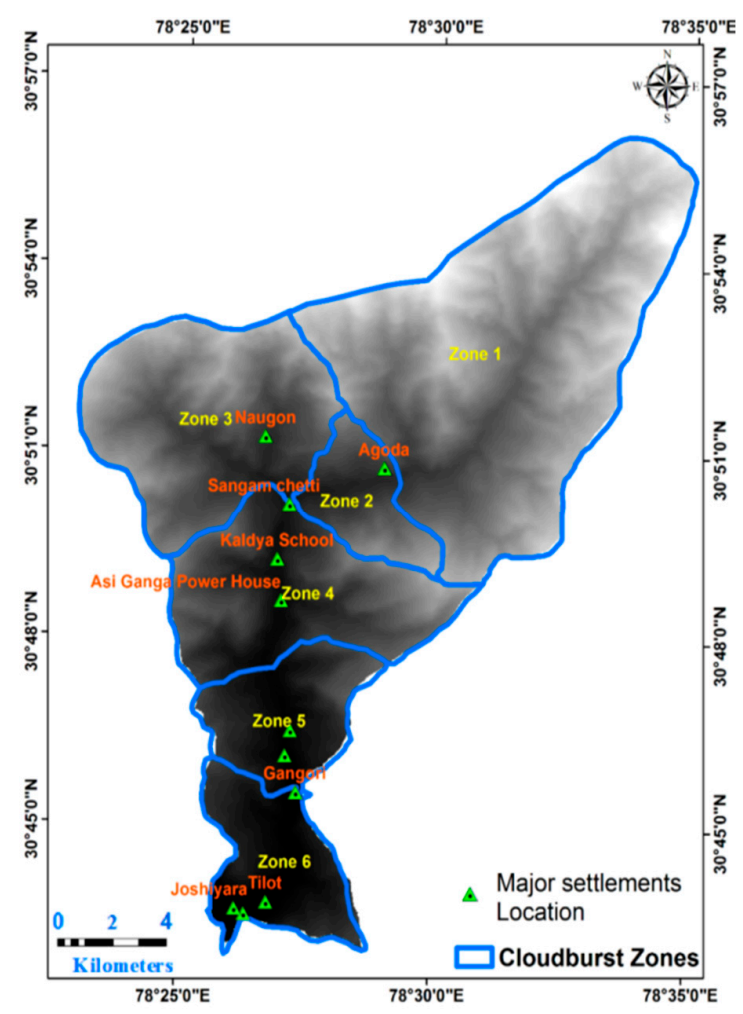

Fig. 6: Clouburst zonation with settlements location. 
Table 2: Catchment detail of each zone in Assi Ganga basin

\begin{tabular}{|c|c|c|c|c|c|c|}
\hline S.No: & Name & $\begin{array}{c}\text { No of } \\
\text { settlements }\end{array}$ & $\begin{array}{c}\text { Area } \\
\left.\mathbf{( k m}^{2}\right)\end{array}$ & $\begin{array}{c}\text { Time of } \\
\text { Concentration } \\
(\mathbf{m i n})\end{array}$ & $\begin{array}{c}\text { Base flow } \\
\text { in } \\
\text { Monsoon } \\
\left(\mathbf{m}^{3} / \mathbf{s}\right)\end{array}$ & Runoff coefficient \\
\hline 1 & Zone 1 & 00 & 73.667 & 81.7 & 10 & 0.234 \\
\hline 2 & Zone 2 & 20 & 11.212 & 9.45 & 10 & 0.264 \\
\hline 3 & Zone 3 & 07 & 39.730 & 29.21 & 10 & 0.298 \\
\hline 4 & Zone 4 & 83 & 32.008 & 30.46 & 10 & 0.398 \\
\hline 5 & Zone 5 & 103 & 16.495 & 16.59 & 10 & 0.25 \\
\hline 6 & Zone 6 & 213 & 16.823 & 20.45 & 10 & 0.402 \\
\hline
\end{tabular}

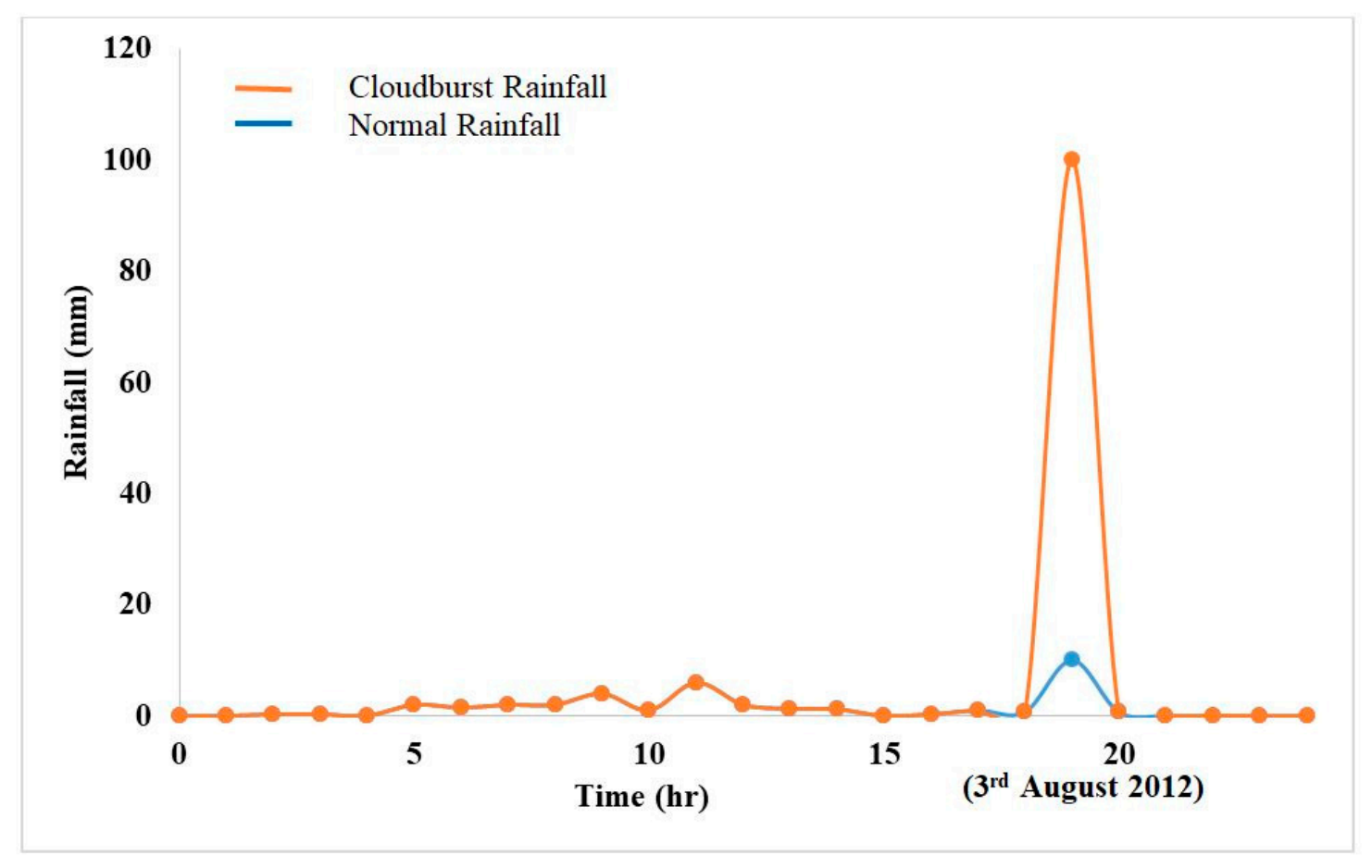

Fig. 7: Rainfall intensity in Zone 1 and rest of the zones

195 It was observed from results that there was an unusual high discharge on $3^{\text {rd }}$ August 2012 in 196 Asi Ganga valley and the discharge at Sangamchetty abruptly increased at 20:30 Hrs. The 197 discharge rise from $50 \mathrm{~m}^{3} / \mathrm{s}$ to $549.164 \mathrm{~m}^{3} / \mathrm{s}$ (an increase about 11 times) within $1 \mathrm{hr}$. The 198 discharge at Joshiyara rose from $600 \mathrm{~m}^{3} / \mathrm{s}$ to $3378.69 \mathrm{~m}^{3} / \mathrm{s}$ (an increase of about more than 5 199 times) within $4 \mathrm{hr}$. Similarly the peak discharges observed at Gangori (21:40 Hrs), Tilot (22:00 $200 \mathrm{Hrs})$ and Joshiyara $(22: 05 \mathrm{Hrs})$ are $582.848 \mathrm{~m}^{3} / \mathrm{sec}, 3363.05 \mathrm{~m}^{3} / \mathrm{sec}$ and $3378 \mathrm{~m}^{3} / \mathrm{sec}$ 201 respectively. The water level at different locations rose from 3 to 5 meters in Asi Ganga basin 202 and up to $7.5 \mathrm{~m}$ in Bhagirathi river. Water level at Uttarkashi locations thus rises as much as 4 203 meters above the danger level. The velocity of flow in the river channel observed to increase 204 from 2 to $12 \mathrm{~m} / \mathrm{s}$ and the flood width increase from 5 to $10 \mathrm{~m}$ from river banks. The time series 205 profile of discharge at Sangamchetty and Gangori in Asi basin is shown in Fig. 8. The time 206 series profile of Gegat and Joshiyara in Bhagirathi River is shown in Fig. 9. 


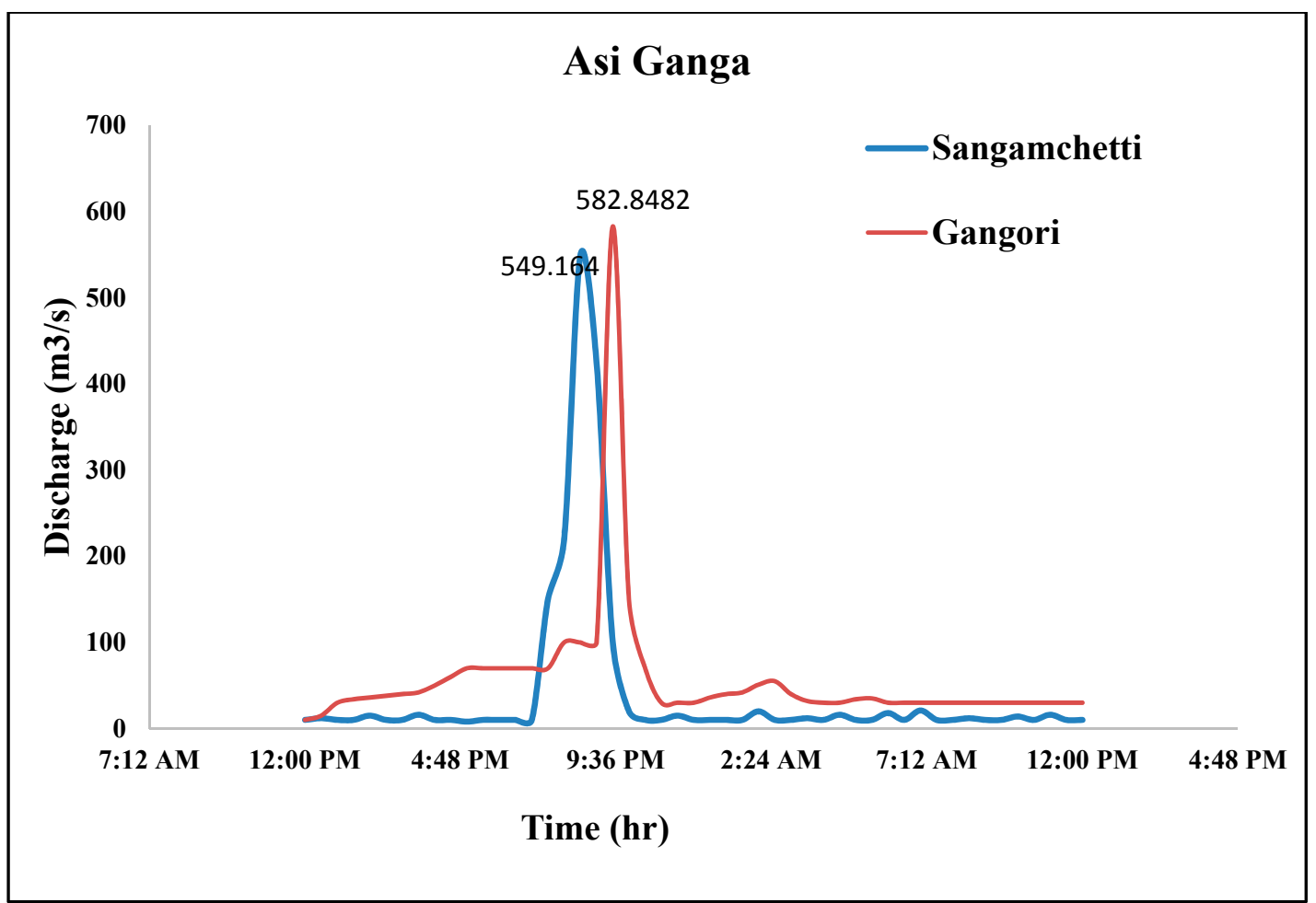

Fig. 8: Discharge in Asi Ganga River

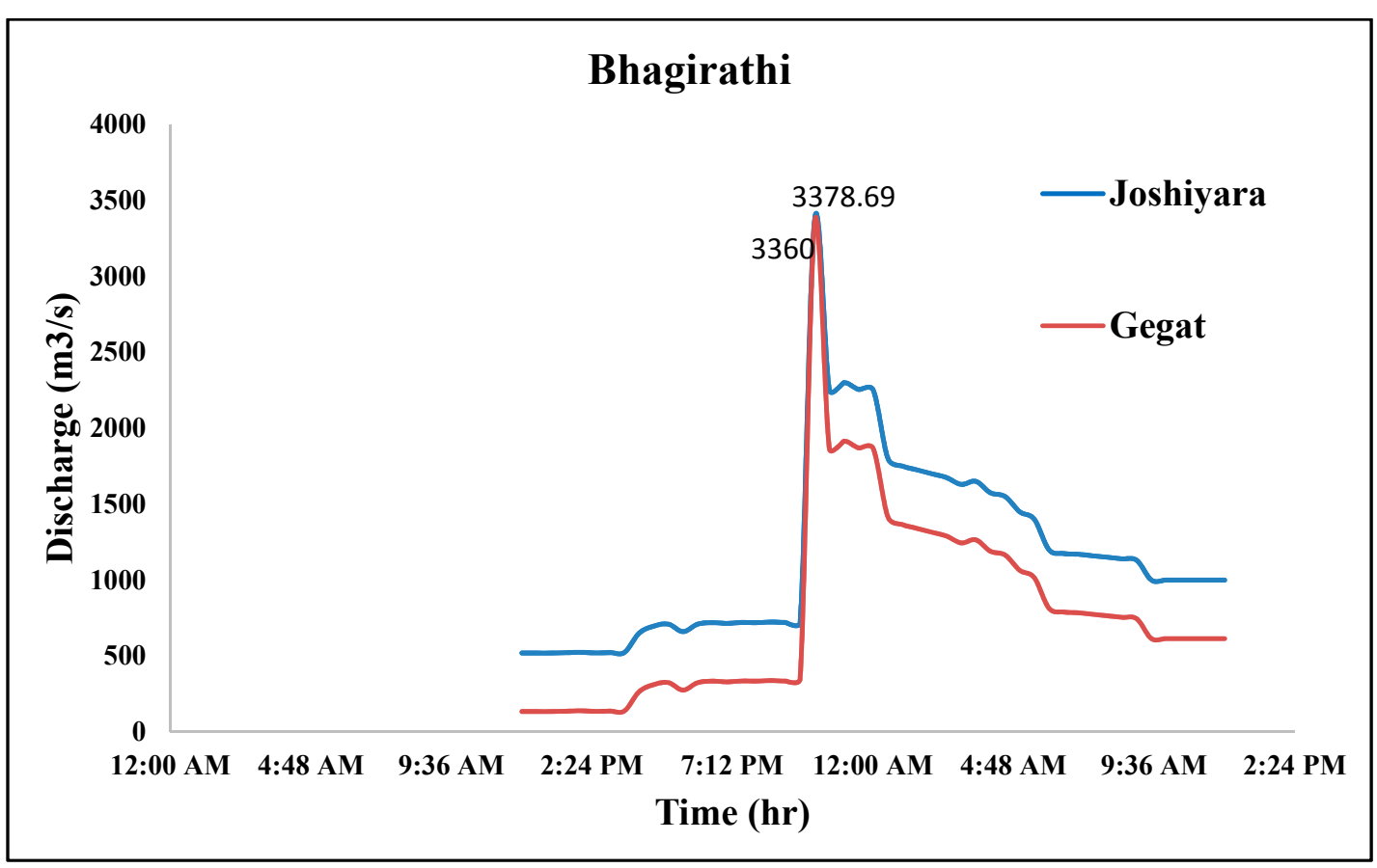

Fig. 9: Discharge in Bhagirathi River

209 Comparison of Hydrological parameters in normal days of South west monsoon season and in

210 case of cloudburst is shown in Table 3. The Longitudinal profile of overtopping water level at 
211 Sangamchetty, Gangori in Asi ganga Basin and Tilot, Joshiyara in Bhagirathi river are shown

212 in Fig.10 (a) \& (b) and Fig. 11(a) \& (b) respectively.

213 Table 3: Comparison of Hydrological parameters in Monsoon season with Cloudbusrt

\begin{tabular}{|c|c|c|c|c|c|c|c|c|c|}
\hline \multirow{3}{*}{$\begin{array}{l}\text { S.No. } \\
1\end{array}$} & \multirow{3}{*}{$\begin{array}{l}\text { Location } \\
\begin{array}{l}\text { Sangam } \\
\text { chetty }\end{array} \\
\end{array}$} & \multicolumn{2}{|c|}{$\begin{array}{c}\text { Discharge } \\
\left(\mathrm{m}^{3} / \mathrm{sec}\right)\end{array}$} & \multirow{2}{*}{\multicolumn{2}{|c|}{$\begin{array}{c}\begin{array}{c}\text { Flow velocity } \\
(\mathbf{m} / \mathbf{s})\end{array} \\
\text { Monsoon Cloudburst }\end{array}$}} & \multicolumn{2}{|c|}{$\begin{array}{l}\text { Flow width } \\
\text { (m) }\end{array}$} & \multicolumn{2}{|c|}{$\begin{array}{c}\text { Water level } \\
\text { (m) }\end{array}$} \\
\hline & & Monsoon & Cloudburst & & & Monsoon & Cloudburst & Monsoon & Cloudburst \\
\hline & & 50 & 549.164 & 6.0 & 12.54 & 25 & 65.23 & 1.5 & 4 \\
\hline 2 & $\begin{array}{l}\text { Asi Ganga } \\
\text { powerhouse }\end{array}$ & 52 & 559.384 & 6.0 & 10.4 & 25 & 92.12 & 1.5 & 4 \\
\hline 3 & Gangori & 76 & 582.848 & 6.5 & 10.18 & 40 & 75.85 & 1.25 & 5.1 \\
\hline 4 & Tilot & 655 & 3363.05 & 5.0 & 8.36 & 70 & 134 & 1.25 & 7.05 \\
\hline 5 & Joshiyara & 662 & 3378.69 & 5.0 & 7.4 & 120 & 162.35 & 1.25 & 6.9 \\
\hline
\end{tabular}

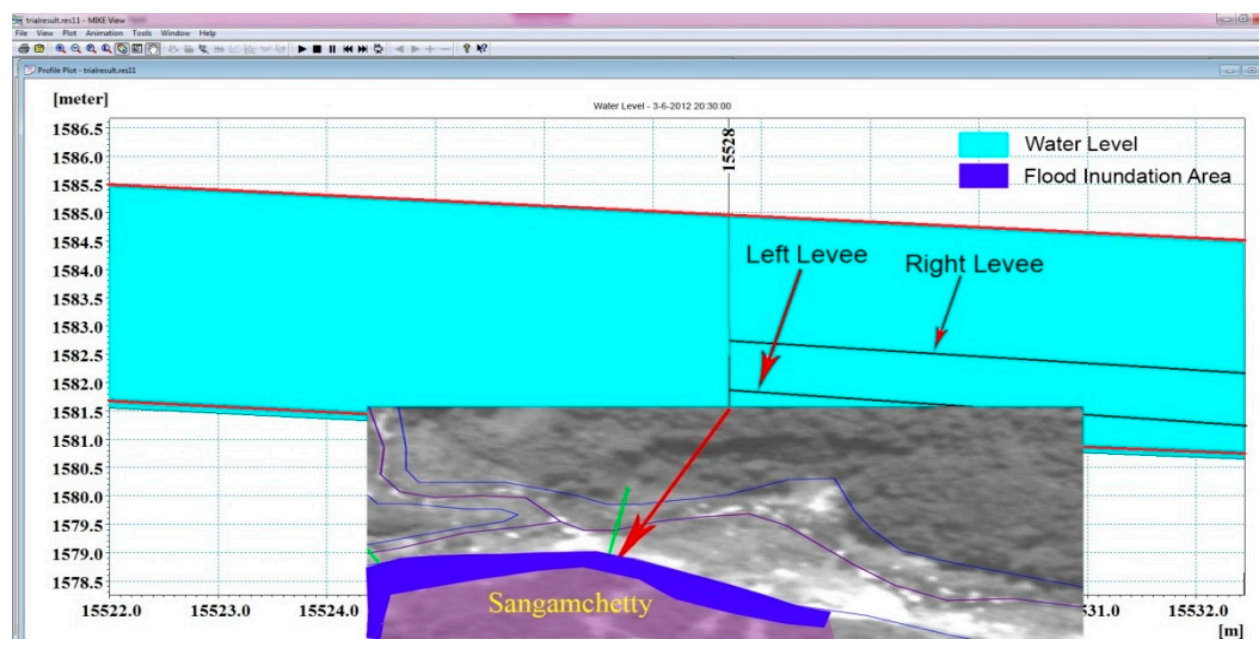

214 Fig.10 (a) : Map showing location of flood Overtopping at Sangamchetty of Asi Ganga River

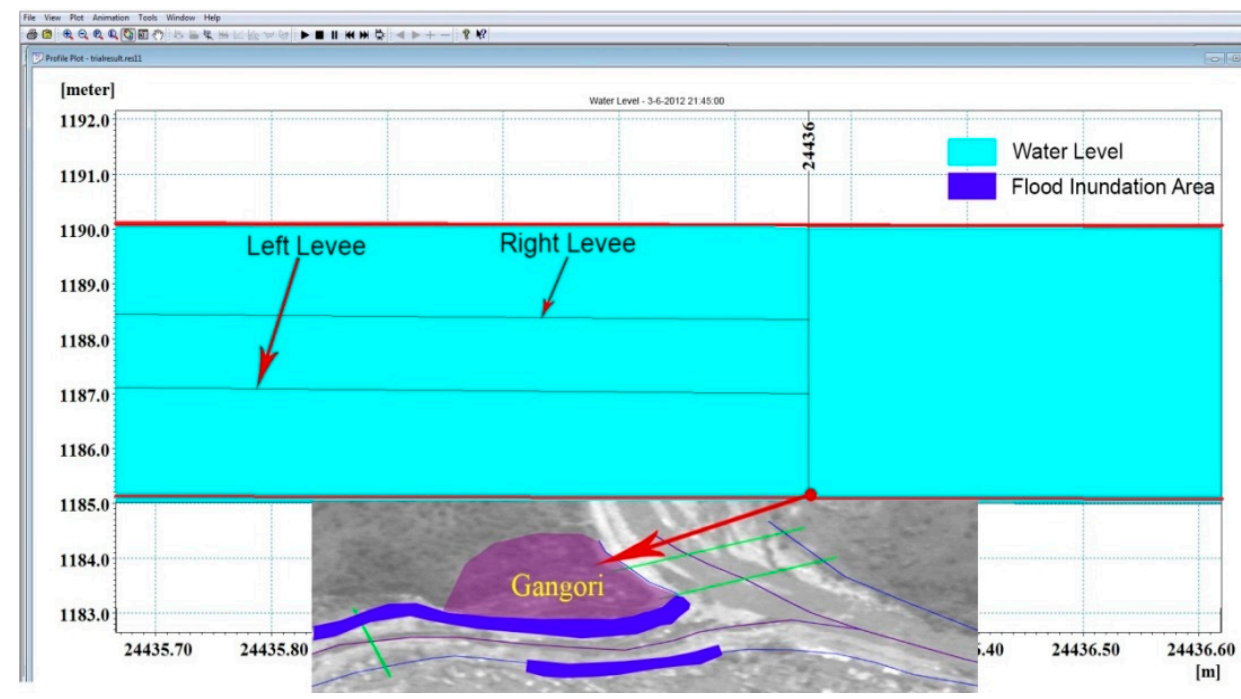

215 Fig.10 (b) : Map showing location of flood Overtopping at Gangori of Asi Ganga River 


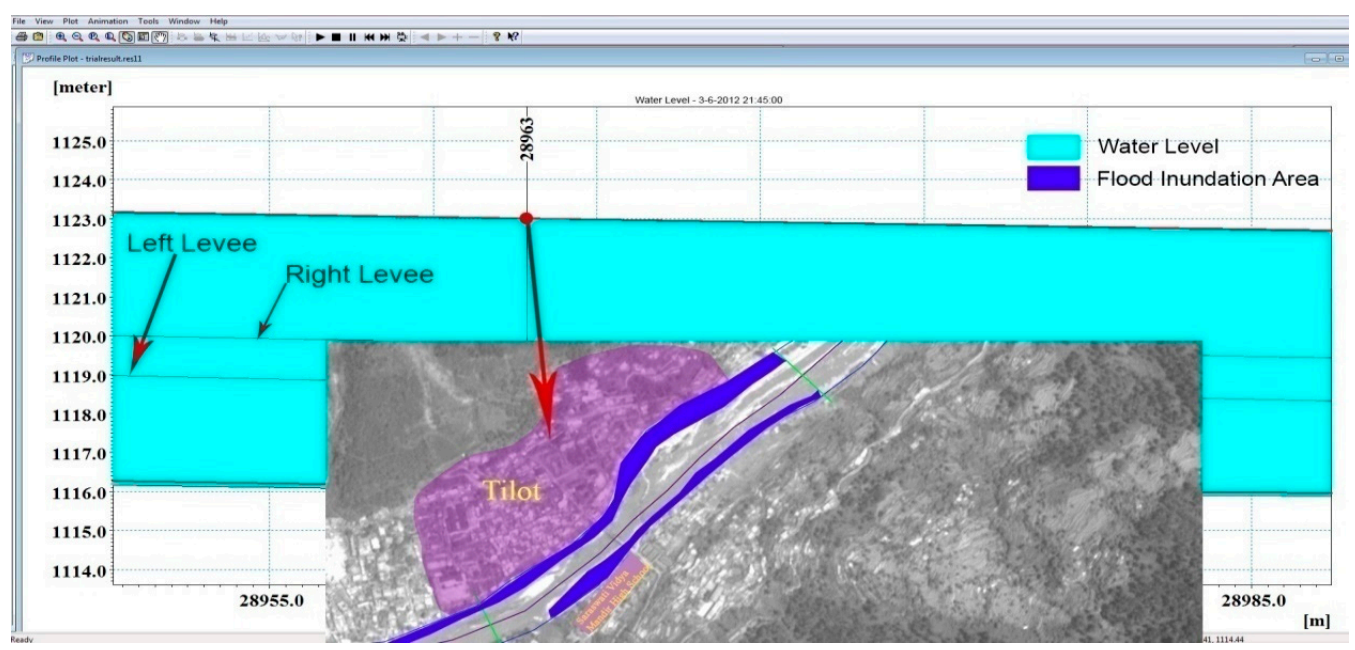

216 Fig.11 (a) : Map showing location of flood Overtopping at Tilot of Bhagirathi River

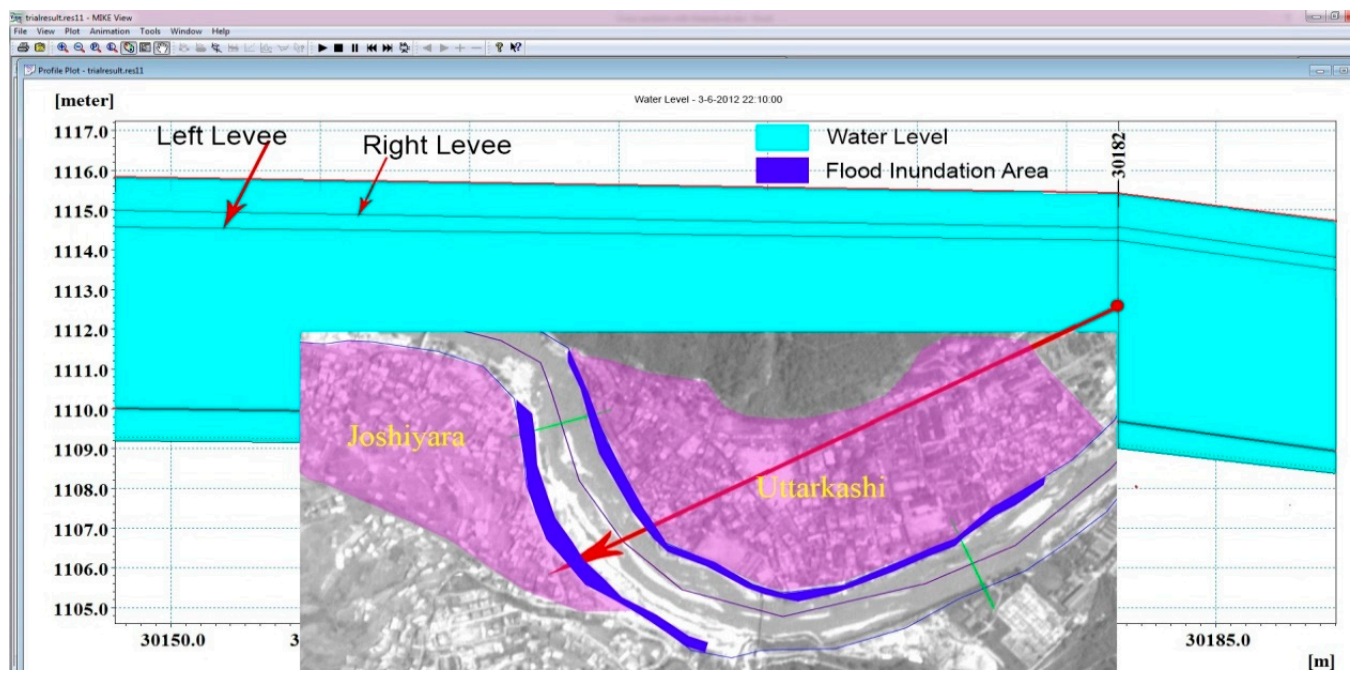

217 Fig.11 (b) : Map showing location of flood Overtopping at Joshiyara of Bhagirathi River

\section{$218 \quad 3.3$ Calibration of the Model}

219 The roughness co-efficient value ' $\mathrm{N}$ ' was used to observe the relationship between the 220 roughness of channel and discharge amount for 2013 datasets. Three values $0.015,0.08$ and 2210.45 are used globally for this purpose. No such change in peak discharges was found as given 222 in Table 4. Among these values, 0.045 gave most suitable output as shown in the validation 223 part. The values were taken globally in the model because the channel morphology was almost 224 similar throughout the reaches. The fully dynamic energy (momentum) was distributed and so, 225 no such changes in simulated discharges were observed after a dramatic change in roughness.

Table $4 \mathrm{~N}$ values and discharge $\left(\mathrm{m}^{3} / \mathrm{s}\right)$

\begin{tabular}{|c|c|c|c|c|c|}
\hline \multirow{2}{*}{ S.No. } & \multirow{2}{*}{ Location } & \multicolumn{4}{|c|}{ Discharge $\left(\mathrm{m}^{3} / \mathrm{s}\right)$} \\
\hline & & N 0.045 & N 0.08 & N 0.015 & Observed \\
\hline 1 & Sangamchetti & 180.425 & 180.4 & 180.38 & 270.125 \\
\hline 2 & Gegat & 874.23 & 874.205 & 874.19 & 905.608 \\
\hline 3 & Tilot & 1174.65 & 1174.85 & 1174.5 & 1195.6 \\
\hline 4 & Joshiyara & 1174.7 & 1174.65 & 1174.455 & 1195.608 \\
\hline
\end{tabular}


228

229

230

231

232

233

234

235

236

237

238

239

240

241

242

\subsection{Validation of MIKE 11 result} respectively.
243

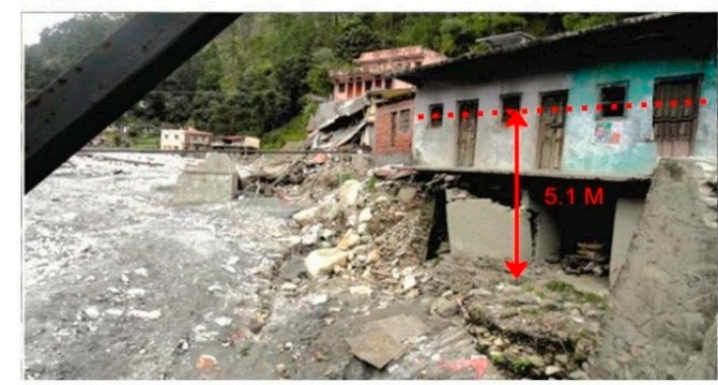

(c)

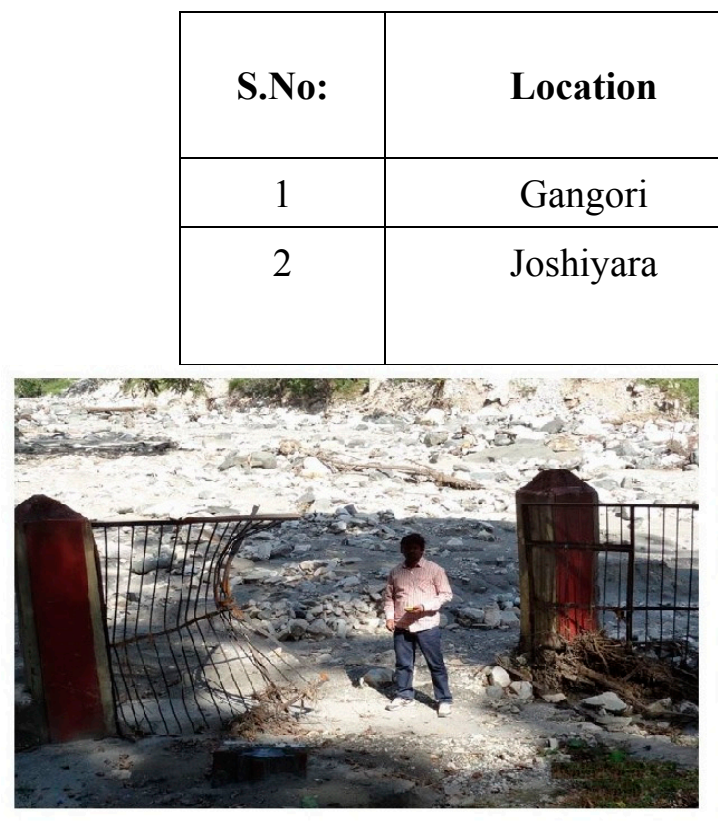

(a)

244

245

246

247

In Cloudburst condition it was difficult to get the data for validation because most of the areas were washed out in Asi Ganga region. For present condition, field visit data and photographs at major locations were used for validation. Few stations were available for validation of simulation data in Asi Ganga basin. Remaining data was validated with the aid of field visit photographs. The peak discharge at Gangori and Joshiyara barrage were used for validation of the simulation model. The validation results are listed in Table 5. In field visit photographs the flood width and water levels marks on the banks and settlements were considered for validation of simulation model results. The field visit data along the main stream channel in Ai Ganga valley and Bhagirath river collected for validation of the model at School entrance of Kaldya village, Asi Ganga power house, settlements near Gangori bridge, Saraswathi vidya mandir near Tilot are shown in Fig. 12 (a), (b), (c) \& (d) and field observations of washed-out areas at Joshiyara market and Joshiyara bridge near Joshiyara barrage are shown in Fig. 13 (e) \& (f)

Table 5. Validation of Simulation model with 2012 Cloudburst data 

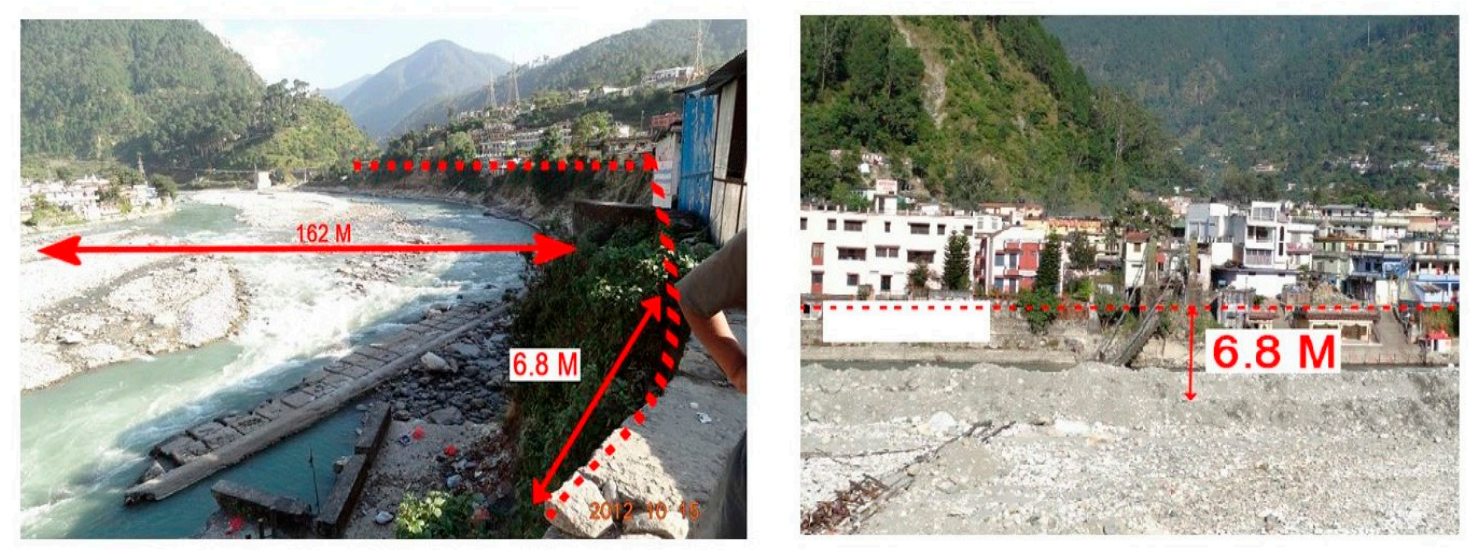

248

249

250

251

252

253

254

255

256

257

258

259

260

261

262

263

264

265

266

267

268

269

270

271

272

273

274

275

276

277

278

Fig. 13: Field observation of washed-out areas at (e) Joshiyara Market and (f) Joshiya bridge

\section{Conclusions}

Future peak discharges due to Cloudburst event indicate the possibility of more serious flash floods in Northern Himalayan region, India. Flood-prone areas in Uttarkashi district, Uttarakhand would be more vulnerable in terms of spatial extent and depth of flooding, due to sudden hitting of Cloudburst leads to increases in peak discharge of the Asiganga and Bhagirathi rivers.

Due to Clousburst event in Asi Ganga basin and heavy rainfall in upper Himalayan region, increase of peak discharge in two rivers (Asi ganga and Bhagirathi) indicate there is an unusual high discharge on 3rd August 2012 in Asi Ganga valley.It is observed that the discharge rise from $50 \mathrm{~m}^{3} / \mathrm{s}$ to $549.164 \mathrm{~m}^{3} / \mathrm{s}$ (an abrupt increase of about 10 times) within $1 \mathrm{hr}$ at Sangamchetty in Asiganga river and at Joshiyara area rise from $600 \mathrm{~m}^{3} / \mathrm{s}$ to $3378.69 \mathrm{~m}^{3} / \mathrm{s}$ (an abrupt increase of about 5 times) within $4 \mathrm{hr}$ in Bhagirathi river. Similarly the peak discharges observed at Gangori (21:40 PM), Tilot (22:00 PM) are $582.848 \mathrm{~m}^{3} / \mathrm{sec}, 3363.05 \mathrm{~m}^{3} / \mathrm{sec}$ respectively. The water level at different locations rise from 3 to 5 meters in Asi Ganga basin and upto $7.5 \mathrm{~m}$ in Bhagirathi river. Water level at Uttarkashi locations rise around 4 meters above the danger level. The velocity of flow in the river channel observed from 2 to $12 \mathrm{~m} / \mathrm{s}$ and the flood width increase from 5 to $10 \mathrm{~m}$ from river banks.

Due to the recent developments in Uttarkashi district, in terms of population and Land use changes more people will be vulnerable for flooding in future, if the intensity of the Cloudburst is maximum. More infrastructure and houses will be exposed to flooding and the likelihood of increased damage is high. This underscores the need for strengthening flood management policies and adaptation measures in the state Uttarakhand, India to reduce increased flood hazard due to Cloudburst.

\section{Acknowledgments:}

The authors would like to thank Uttarakhand Jal Vidyut Nigam Limited (UJVNL) and Northern Division Ganga Canal Roorkee for providing necessary data used for validation of the model. The corresponding author thankful to the authorities of Indian Institute of Technology, Roorkee and National Institute of Hydrology for providing me all necessary assistance in the form of research and guidance. 


\section{Author Contributions:}

280 Vasanta Govind Kumar Villuri, Kamal Jain and Ajay Gairola have got major contributions in 281 this work in conceiving the research, analysing DEM and in preparation of hydrodynamic 282 model. All authors involved in summarizing the results and findings. Vasanta Govind Kumar 283 Villuri, Kamal Jain, Ajay Gairola and Srinivas Pasupuleti are involved in preparing the 284 manuscript.

285 Conflicts of Interest: The authors declare no conflict of interest.

286

287

\section{References:}

[1] Sati, V. P., and R. K. Maikhuri. "Cloudburst: a natural calamity." Him Prayavaran 4, no. 2 (1992): 11-13.

[2] Karimi, Hassan A., and Benjamin H. Houston. "Evaluating strategies for integrating environmental models with GIS: current trends and future needs." Computers, Environment and Urban Systems 20, no. 6 (1996): 413-425.

[3] Walker, S. "Keys to successful implementation of computer aided decision support systems in water resources management." Adv Water Resour Technol (1991): 467-472.

[4] Chow, V. T., D. R. Maidment, and L. W. Mays. "Applied hydrology, 572 pp." Editions McGraw-Hill, New York (1988).

[5] Subramanya, K., (2004), Engineering Hydrology, New Delhi, TataMcGraw-Hill, Second Edition.

[6] Bates, Paul D., and A. P. J. De Roo. "A simple raster-based model for flood inundation simulation." Journal of hydrology236, no. 1 (2000): 54-77.

[7] MIKE11, D. H. I. "Modeling System for Rivers and Channels, User Guide, DHI-Group." (2008).

[8] Billa, Lawal, Shattri Mansor, Ahmad Rodzi Mahmud, and Abdul Halim Ghazali. "Integration of RS, GIS and MIKE 11 Hydrodynamic Modeling for Flood Early Warning: A case study of the Langat river basin Malaysia." (2004).

[9] Agrawal, S.K., Kharya, A.K. and Khattar, R., 2001. Flood Management in Bagmati Basin, Central Water Commission, Bihar, India.

[10] Kusre, B. C., D. C. Baruah, P. K. Bordoloi, and S. C. Patra. "Assessment of hydropower potential using GIS and hydrological modeling technique in Kopili River basin in Assam (India)." Applied Energy 87, no. 1 (2010): 298-309.

[11] Rojanamon, Pannathat, Taweep Chaisomphob, and Thawilwadee Bureekul. "Application of geographical information system to site selection of small run-of-river hydropower project by considering engineering/economic/environmental criteria and social impact." Renewable and Sustainable Energy Reviews 13, no. 9 (2009): 2336-2348. 
314 [12] Connolly, David, S. MacLaughlin, and M. Leahy. "Development of a computer program 315 to locate potential sites for pumped hydroelectric energy storage." Energy 35, no. 1 (2010): $316 \quad 375-381$.

317 [13] Gupta, Vikram, D. P. Dobhal, and S. C. Vaideswaran. "August 2012 cloudburst and 318 subsequent flash flood in the Asi Ganga, a tributary of the Bhagirathi river, Garhwal Himalaya, 319 India." Current Science (2013): 249-253.

320 [14] Arcement, George J., and Verne R. Schneider. "Guide for selecting Manning's roughness 321 coefficients for natural channels and flood plains." (1989).

322 [15] Chow, V.T., Maidment, D. R. \& Mays, L.W, 1995. Handbook of Applied Hydrology. 323 Civil Engineering Series.

324 [16] Saraf, A. K., and P. R. Choudhury. "Integrated remote sensing and GIS for groundwater 325 exploration and identification of artificial recharge sites." International journal of Remote 326 sensing 19, no. 10 (1998): 1825-1841.

327 [17] Ghayoumian, Jafar, B. Ghermezcheshme, Sadat Feiznia, and Ali Akbar Noroozi. 328 "Integrating GIS and DSS for identification of suitable areas for artificial recharge, case study 329 Meimeh Basin, Isfahan, Iran." Environmental Geology 47, no. 4 (2005): 493-500.

330 [18] Srinivasan, R., and B. A. Engel. "Effect of slope prediction methods on slope and erosion 331 estimates." Applied Engineering in Agriculture 7, no. 6 (1991): 779-783.

332 [19] Esri, G. I. S. "Dictionary." Definitions for GIS terms related to operations such as analysis, 333 GIS modeling and web-based GIS, cartography, and Esri software (2014).

334 [20] Dimri, A. P., A. Chevuturi, D. Niyogi, R. J. Thayyen, K. Ray, S. N. Tripathi, A. K. Pandey, 335 and U. C. Mohanty. "Cloudbursts in Indian Himalayas: A review." Earth-Science Reviews 336 (2017).

337 [21] MIKE-11 D. H. I. user's manual, 2000 DHI-Group. 